\title{
Characteristics of Bacterioplankton community, the influencing factors and functional profiles of the Huangshui River on the ecotone zone of Qinghai Plateau and Loess Plateau
}

\section{Qianqian Zhang}

Chinese Academy of Sciences

Zhenbing Wu

Chinese Academy of Sciences

Shenglong Jian

Chinese Academy of Sciences

Kemao Li

Chinese Academy of Sciences

\section{Guojie Wang}

Chinese Academy of Sciences

Jingwen Hao

Chinese Academy of Sciences

Shuyi Wang

Chinese Academy of Sciences

Yaoyao Lin

Chinese Academy of Sciences

Hongtao Guan

Chinese Academy of Sciences

Aihua Li ( $\nabla$ liaihua@ihb.ac.cn )

Chinese Academy of Sciences https://orcid.org/0000-0003-0867-9823

\section{Research Article}

Keywords: Huangshui river, High-throughput sequencing, Bacterioplankton community structure, Environment factors, PICRUSt analysis

Posted Date: February 18th, 2021

DOl: https://doi.org/10.21203/rs.3.rs-203192/v1 
License: (c) (i) This work is licensed under a Creative Commons Attribution 4.0 International License. Read Full License 


\section{Abstract}

Planktonic microorganisms play a key role in environmental and ecological processes in river ecosystems. Molecular techniques are increasingly used for biological monitoring of rivers. Here, the present study used high-throughput sequencing technology to investigate and study the bacterioplankton community of water bodies of the Huangshui River on the ecotone zone of Qinghai Plateau and Loess Plateau. The results indicated that the Huangshui River had lower alpha diversity than other plain rivers. Proteobacteria was the dominant phyla with relative abundance of $77.48 \%$, followed by Firmicutes, Alphaproteobacteria and Gammaproteobacteria were significantly enriched. The predominant bacterial genera were Acidiphilium, Acidocella, Metallibacterium and Acinetobacter. Diverse taxa of potential pathogens, such as Acinetobacter, Pseudomonas, and Aeromonas, were also been identified. The major driving factors for the bacterial community were Cr6+, altitude, and TN. PICRUSt results revealed that a substantial number of functional profiles were involved in human diseases and antibiotic resistance. Therefore, further studies were needed to isolate these potentially pathogenic organisms, as this will help protect the lives of communities using Huangshui River. The present study provided a certain theoretical basis for understanding the microbial ecology and environmental protection in the Huangshui River on the ecotone zone of Qinghai Plateau and Loess Plateau.

\section{Introduction}

Microorganisms are primary decomposers of organic compounds in natural ecosystems, participating in regional climate formation, geochemical cycle, and biological evolution, and playing a vital role in natural ecosystems [1]. The distribution of microorganisms has attracted increasing interest in the last decade, and diversity patterns of microbial communities have been widely observed [2]. Bacterioplanktons are essential players in aquatic ecosystems [3], which are a fundamental and highly variable component of river ecosystems, exhibiting a comprehensive response to environmental pressure and disturbances [49]. Changes in river water quality and ecological environment caused by human activities will lead to variations in the microbial community structure [10]. By analyzing the changes in the microbial community structure, the state of river ecosystem health can be evaluated [11].

Qinghai Province, as the "Chinese water tower", is located in the west of China and in the northeastern part of the Qinghai-Tibet Plateau. Its river ecosystem plays an important role in the ecological status of the whole province and even the whole China. The Huangshui River, is the largest tributary in the upper reaches of the Yellow River. It locates in the eastern part of Qinghai Province $\left(36^{\circ} 02^{\prime}-38^{\circ} 20^{\prime} \mathrm{N}, 98^{\circ} 54^{\prime}-\right.$ $103^{\circ} 24^{\prime} \mathrm{E}$ ), at an altitude of 1,650 to 4400 m originating from the Baohutu Mountain in Haibei County, Qinghai Province and flowing into the Yellow River in Gansu Province [12]. Since the 20th century, the rapid development of human activities in industry, agriculture, mining, and overgrazing has caused outstanding problems in the aquatic environment, including reduction of water resources, deterioration of water quality, and decline of aquatic biodiversity. 
At present, the aquatic ecosystem and microbial community of Huangshui River have not been studied. In this study, 16S rRNA gene high-throughput sequencing was conducted in the upper reaches of Huangshui Rivers to gain in-depth insight into possible environmental factors shaping variations in the bacterioplankton community structure. This study can also provide comprehensive understanding of the specific bacterioplankton roles in biogeochemical cycling and determine the potential effects of river regulations on bacterioplankton communities.

\section{Materials And Methods}

\section{Study sites and sample collection}

As the largest tributary of the upper reaches of the Yellow River, the Huangshui River is located in the intersecting zone of the Qinghai-Tibet Plateau and Loess Plateau. The terrain in the basin is high in the northwest, and low in the southeast with high mountains and deep valleys. The climate belongs to the plateau arid and semi-arid continental climate, with vertical changes and large regional differences because of the diversity of the local topography. The temperature decreases as it goes upstream, whereas the precipitation increases, and the evaporation decreases. Moreover, humid marshes are found. The average annual temperature in the basin is $0.6^{\circ} \mathrm{C}-7.9^{\circ} \mathrm{C}$, and the average annual precipitation is $360-$ $540 \mathrm{~mm}$ [13]. Eight sampling sections, numbered from HS1 to HS8, were set up along the midstream of the Hungshui River $\left(100^{\circ} 31^{\prime}-102^{\circ} 50^{\prime} \mathrm{E}, 36^{\circ} 19^{\prime}-37^{\circ} 44^{\prime} \mathrm{N}\right)$ (Fig. 6). Two liters of water samples was collected from $2 \mathrm{~m}$ of the middle point of the river. One liter of water sample was subsequently filtered on board through $0.22 \mu \mathrm{m}$ polycarbonate membranes (Millipore Corporation, Billerica, MA, USA). Filters were frozen at $-80{ }^{\circ} \mathrm{C}$ until DNA extraction.

\section{Physicochemical analyses}

Many environmental factors are related to the distribution of planktonic bacterial communities, but many of them have strong contributory relationships. The environmental factors screened in this study were $\mathrm{pH}$, altitude, $\mathrm{TN}, \mathrm{TP}, \mathrm{NH}_{4}{ }^{+}-\mathrm{N}, \mathrm{Pl}$, and $\mathrm{Cr}^{6+}$. Water chemistries such as temperature, $\mathrm{pH}$, and dissolved oxygen (DO) were monitored using a YSI Pro2030 (YSI Incorporated, Ohio, USA). Total phosphorus (TP), total nitrogen (TN), permanganate index $\left(\mathrm{COD}_{\mathrm{Mn}}\right), \mathrm{NH}_{4}{ }^{+} \mathrm{N}, \mathrm{As}$, and metal ions $\left(\mathrm{Cr}^{6+}, \mathrm{Cu}, \mathrm{Zn}, \mathrm{Pb}, \mathrm{Cd}\right.$, and $\left.\mathrm{Hg}\right)$ were analyzed by Qinghai Fishery Environment Monitoring Station. TP, TN, and $\mathrm{Cr}^{6+}$ were analyzed by a dual beam UV-visible spectrophotometer (TU-1901, T9CS). As and $\mathrm{Hg}$ were analyzed by an atomic fluorescence photometer (AFS-230E), and the metal ions were determined by a graphite furnace flame atomic absorption spectrophotometer (ICE-3500, AA6300).

\section{DNA extraction, polymerase chain reaction (PCR), and Illumina Miseq sequencing}

Microbial community genomic DNA was extracted from the water samples using the E.Z.N.A.® water DNA Kit (Omega Bio-tek, Norcross, GA, USA) in accordance with the manufacturer's instructions. The final DNA concentration and purification were determined by a NanoDrop 2000 UV-vis spectrophotometer 
(Thermo Scientific, Wilmington, USA), and DNA quality was checked by $1 \%$ agarose gel electrophoresis. The V3-V4 hypervariable regions of the bacteria $16 \mathrm{~S}$ rRNA gene were amplified with primers $338 \mathrm{~F}\left(5^{\prime}-\right.$ ACTCCTACGGGAGGCAGCAG-3') and 806R (5'-GGACTACHVGGGTWTCTAAT-3') by a thermocycler PCR system (GeneAmp 9700, ABI, USA). PCR reactions were conducted using the following program: 3 min of denaturation at $95^{\circ} \mathrm{C}, 27$ cycles of $30 \mathrm{~s}$ at $95^{\circ} \mathrm{C}, 30 \mathrm{~s}$ for annealing at $55^{\circ} \mathrm{C}, 45 \mathrm{~s}$ for elongation at $72{ }^{\circ} \mathrm{C}$, and a final extension at $72{ }^{\circ} \mathrm{C}$ for $10 \mathrm{~min}$. PCR reactions were performed in triplicate $20 \mu \mathrm{L}$ mixtures containing $4 \mu \mathrm{L}$ of $5 \times$ FastPfu buffer, $2 \mu \mathrm{L}$ of $2.5 \mathrm{mM}$ dNTPs, $0.8 \mu \mathrm{L}$ of each primer $(5 \mu \mathrm{M}), 0.4 \mu \mathrm{L}$ of FastPfu polymerase, and $10 \mathrm{ng}$ of template DNA. The resulting PCR products were extracted from $2 \%$ agarose gel, further purified using the AxyPrep DNA Gel Extraction Kit (Axygen Biosciences, Union City, CA, USA), and quantified using QuantiFluor ${ }^{\text {TM}}$-ST (Promega, USA) according to the manufacturer's protocol.

Purified amplicons were pooled in equimolar and paired-end sequenced $(2 \times 300)$ on an Illumina MiSeq platform (Illumina, San Diego, USA) according to the standard protocols by Majorbio Bio-Pharm Technology Co. Ltd. (Shanghai, China). The raw reads were deposited in the NCBI Sequence Read Archive database (Accession Number: SRP294338).

\section{Processing of sequencing data}

Raw fastq files were demultiplexed, quality-filtered by trimmomatic, and merged by FLASH with the following criteria: (i) the 300 bp reads were truncated at any site receiving an average quality score of < 20 over a 50 bp sliding window, and the truncated reads shorter than 50 bp were discarded; reads containing ambiguous characters were also discarded; (ii) only overlapping sequences longer than $10 \mathrm{bp}$ were assembled according to their overlapped sequence. The maximum mismatch ratio of the overlap region was 0.2 . Reads that could not be assembled were discarded; (iii) Samples were distinguished according to their barcode and primers, and the sequence direction was adjusted; exact barcode matching was performed, and two mismatched nucleotides.

Operational taxonomic units were clustered with 97\% similarity cutoff using UPARSE (version7.1 http://drive5.com/uparse/), and chimeric sequences were identified and removed using UCHIME. The taxonomy of each $16 \mathrm{~S}$ rRNA gene sequence was analyzed by the RDP classifier algorithm (http://rdp.cme.msu.edu/) against the Silva (SSU123) 16S rRNA database using a confidence threshold of $70 \%$.

\section{Statistical analysis}

All samples were rarefied at 56,234 sequences per sample to retain as many samples as possible. We evaluated the alpha-diversity through the community richness indices (Ace, Chao), community diversity indices (Shannon, Simpson), and Good's coverage. Non-metric Multidimensional Scaling (NMDS) was carried out on OTUs data using Bray-Curtis distance matrices to examine the difference in bacterial community between water samples. Environmental factors can be screened through variance inflation factor analysis to retain those with low collinearity. The environmental factors screened in this study are $\mathrm{PI}, \mathrm{Cr}^{6+}$, altitude, $\mathrm{pH}, \mathrm{TN}, \mathrm{TP}$, and $\mathrm{NH}_{4}{ }^{+}-\mathrm{N}$. Canonical correspondence analysis (CCA) was performed to 
determine the environmental variables associated with changes in the bacterioplankton community structure using the vegan package. Linear discriminant analysis (LDA) effect size (LEfSe) is an algorithm for high-dimensional biomarker discovery and explanation, which identifies genomic features (genes, pathways, or taxa) characterizing the differences between two or more biological conditions [14]. In the present study, LEfSe was conducted to identify differential microbial functions between the main stream and tributary with the alpha parameter of 0.05 and an LDA threshold value of 2.0. Differences between two independent groups were evaluated by Mann-Whitney $U$ test. PICRUSt (phylogenetic investigation of communities by reconstruction of unobserved states) was used to predict microbial functions and metabolic pathways [15].

\section{Results}

\section{Environmental characteristics}

Environmental characteristics of the samples from the eight investigated sites are shown in Table 1. The surface water temperature ranged from $6.8^{\circ} \mathrm{C}$ to $17.2^{\circ} \mathrm{C}$, and the $\mathrm{pH}$ ranged from 8.34 to 8.47 , indicating a weak alkaline. The HS1 and HS2 sites had a significantly low level of Hg and As (Mann-Whitney U test, $p<0.05)$. From the upper reaches to the lower reaches of the Datong River (HS7-HS3), the DO level showed a downward trend. On the contrary, the TN level showed an upward trend. $\mathrm{The}^{\mathrm{Cr}}{ }^{6+}, \mathrm{Cu}, \mathrm{Zn}, \mathrm{Pb}$ and Cd levels remained consistent in the eight investigated sites.

\section{Community structure, richness, and diversity of bacterioplankton}

After quality filtering, 497,604 valid reads (ranging from 56,234 to 69,445 per sample) were generated in total from eight sampling sites along the Huangshui River. All the samples were randomly resampled to 56,234 reads, and the reserved sequences were clustered into a total of 2384 OTUs. Good's coverage (all samples, $99.80 \% \pm 0.14 \%$ ) suggested that the majority of the microbial species present in the samples were identified. The rarefaction curves tended to approach the saturation plateau, indicating a sufficient sampling depth of all libraries. The microbial diversity index listed in Table 2 comprised community richness indices (Ace, Chao) [16] and community diversity indices (Shannon, Simpson) [17]. As shown in Table 2, the Shannon index of the water samples of HS4, HS6 and HS8, which indicated bacterial diversity, were significantly (LDA>2) higher than that of other sampling sites. Except for HS5, HS1 and HS2 had low a diversity. The community of HS6 had the maximum richness and diversity, with Chao index of 1764.3472 and Shannon index of 5.0497.

The phylogenetic classification results showed a total of 34 microbial phyla in all samples, including 78 classes, 216 orders, 386 families, 821 genera, and 1309 species. Differences in bacterial community composition were observed among different groups. The bacterial community composition at the phylum level in different samples is shown in Figure 1. Across all sampling sites, bacterioplankton communities were dominated by Proteobacteria and Firmicutes, and the relative abundance of these two phyla accounted for $77.48 \%$ and $12.08 \%$, respectively. Notably, the abundance of Proteobacteria in HS1, HS2, 
HS5 and HS7 sampling points was above $99 \%$, and it was as high as $99.98 \%$ at HS5 sampling sites. Among the Proteobacteria, the most abundant class was Alphaproteobacteria (up to $95.93 \%$ ), followed by Gammaproteobacteria (up to $55.16 \%$ ), Clostridia (up to $28.96 \%$ ) and Bacilli (up to $17.12 \%$ ). Proteobacteria dominated the sampling sites, but its classes were distributed differently, with Gammaproteobacteria and Clostridia predominant in HS6 and HS4, respectively, whereas Alphaproteobacteria was predominant in the remaining sampling sites. Notably, the abundance of Alphaproteobacteria was markedly different among the eight sampling sites with a higher amount at sites HS5 and HS7 and a lower amount at site HS4 and HS6.

The bacterioplankton community structure was analyzed at the genus level using a heat map of the top 50 genera for different sites Figure 2. Of the six most abundant genera, two belonged to Alphaproteobacteria, and four belonged to Gammaproteobacteria. Interestingly, the top three abundance genera had polar distribution at each sampling point. For example, the abundance of Acidocella at the HS5 sampling point was as high as $95.9 \%$, and the sum of the abundances of Acidiphillum and Metallibacerium at the HS1 and HS2 sampling points was $97.52 \%$ and $99.3 \%$, respectively. Moreover, the abundance of Acidiphillum and Acidocella at the HS7 sampling point was $92.49 \%$. However, the abundances of the three genera at the sampling points of HS4, HS6, and HS8 were $1.3 \%, 0.74 \%$, and $0.54 \%$, respectively. Notably, the most abundant genus at the HS6 sampling site was Aeromonas, and some species of this genus could cause enteritis, sepsis and other diseases in humans and animals.

\section{Correlation analysis of bacterioplankton communities and environmental factors}

Canonical correspondence analysis (CCA) was performed to determine the environmental variables associated with changes in the bacterioplankton community structure (Figure 3 ). The first axis explained $31.22 \%$ of the total variance, whereas the second axis explained $26.69 \%$, indicating that the selected environmental factors drive the differences of bacterioplankton community structures. Most variances can be explained by altitude $\left(\mathrm{R}^{2}=0.577, p=0.123\right), \mathrm{Cr}^{6+}\left(\mathrm{R}^{2}=0.534, p=0.16\right), \mathrm{PI}\left(\mathrm{R}^{2}=0.502, p=0.159\right)$, and TP $\left(\mathrm{R}^{2}=0.427, p=0.234\right)$. Acidiphilium and Metallibacterium were found to be more related to TP and $\mathrm{Cr}^{6+}$, whereas Acinetobacter and Romboutsia were positively related to TN. Although not significant, Aeromonas and Legionella seemed to be positively correlated with altitude and PI and negatively correlated with TP and $\mathrm{Cr}^{6+}$.

\section{Biogeography patterns of bacterial communities}

Non-metric multidimensional scaling was applied using the Bray-Curtis distance to identify the community compositions of all samples (Figure 4). The first axis revealed that the five sampling sites of the Datong River did not cluster. However, the main stream sites of the Huangshui River (HS1 and HS2) clustered with HS5 and HS7, which were from the Datong River. The HS8 site from the Baoku River clustered with the other three sampling sites of the Datong River (HS3, HS4 and HS6).

\section{Functional prediction by PICRUSt}


Community prediction analysis using PICRUSt was performed to determine the function of the observed bacterioplankton. The top abundance functional pathways have been presented in Figure 5. Of all the different functional pathways identified, carbohydrate metabolism, amino acid metabolism, global and overview maps, energy metabolism and membrane transport were substantially over-represented compared with other pathways. The main stream microbial assemblages had high abundance of Kos, which belonged to human diseases and cellular processes. Similarly, the tributary had high abundance of Kos, which belonged to metabolism (Fig. S1). Given the importance of water quality to human health, we targeted human diseases and resistance functional classes (Table 3). However, no significant differences between main stream and tributary microbial assemblages were found in the relative abundance of three core resources metabolism pathways, namely, carbohydrate metabolism, energy metabolism, and amino acid metabolism.

\section{Discussion}

Macrobenthic community compositions in the upper reaches of the Huangshui River have previously been reported. These works have only provided the community structure of macrobenthos, assessment of ecosystem health, and quality of water in the Huangshui River $[18,19]$. However, bacteria play a critical role in environmental and ecological processes in river ecosystems. Exploring the composition of aquatic planktonic bacteria can enhance the understanding of accurate microbial distribution patterns and help to comprehensively understand the Huangshui River. Here, as a complement to previous studies, this study assessed the pattern of the bacterioplankton community and the relationship with environmental factors. Based on previous reports, this study was the first to investigate the bacterioplankton community in the upper reaches of the Huangshui River.

The Chao 1 richness and Shannon index in the river samples were lower than that of other rivers in the previous papers. For instance, Fan et al. [20] reported that the Chao1 and Shannon indices of the planktonic bacterial community in the upper section of the tidal reach in the Yangtze River ranged from 764.33 to 861 and 4.36 to 4.72 , respectively. Hauptmann et al. [21] investigated the bacterioplankton community along a small Arctic River and revealed that the Chao1 indices ranged from 1408 to 19117 OTUs, and the Shannon indices ranged from 5.6 to 10.8 per sample. Yang et al. [22] reported that the Chao1 and Shannon indices of bacteria in the Songhua River, one of the seven largest rivers in China, ranged from 1249.26 to 5780.18 and 2.85 to 5.21 , respectively, which were much higher than those of the Huangshui River. On the contrary, the Chao 1 and Shannon indices ranged from 300.546 to 2014.803 and 0.789 to 5.529 , respectively, which were similar to the Heihe River, also known as the Plateau river [23]. The low alpha diversity in Plateau Rivers may be due to the special geographical environment, low temperature and high altitude, which are not conducive to bacterial growth.

The drop in alpha diversity at the input sites from the tributary of the Datong River (HS5) indicates that the tributary inputs less diverse bacterial communities into the main stream of the Datong River. The diversity of the two tributaries of the Datong River and Baoku River is significantly higher than that of the main stream of the Huangshui River, but the diversity of HS1 and HS2 has not increased because of the 
confluence of the two tributaries. This result indicates that the volume of water from the main stream of the Huangshui River is not diluted by the tributary community. Moreover, the high diverse communities from the Datong River and Baoku River are concealed by the low diversity of the main stream of the Huangshui River.

The bacterial community in water samples was different with regard to phylum, genus, and OUT (Figs. 1, 2, and 4). High-throughput sequencing data showed that the dominant phylum was Proteobacteria, with up to $99.98 \%$ of the sequences, followed by Firmicutes (49.38\%). This result is similar to the results of the local and international study of planktonic bacterial communities in rivers [24] and lakes [25, 26]. The relative abundance of Proteobacteria was $77.48 \%$, which was found to be the most abundant phylum in wastewater [27, 28]. However, notably, proteobacteria, which is the dominant phylum, consists of Alphaproteobacteria and Gammaproteobacteria, and the relative content of the two classes of bacteria is as high as $76.82 \%$. Moreover, Alphaproteobacteria and Gammaproteobacteria can be found in freshwater and seawater, but they are more abundant in seawater [29-31]. This finding may be due to the salt mineral resources such as gypsum and calcium Glauber's salt mine, which are widely distributed along the banks of the Huangshui River. Furthermore, the microbial composition of the Huangshui River is significantly different from other freshwater rivers at the class level.

At the genus level, the top six species in relative abundance at each sampling site are Acidiphilium, Acidocella, Metallibacterium, Acinetobacter, Pseudomonas, and Aeromonas. According to previous studies, Acidiphilium, Acidocella, and Metallibacterium dominated microbial communities within mineralleaching environments or acidic aquatic environments [32]. The $\mathrm{pH}$ of the Huangshui River is 8.34-8.47, indicating a weak alkaline, and the content of metal ions is low, which is not the most suitable condition for the enrichment of these microorganisms. Apart from its unique hydrology, biology, climate, and landform, the study area has notable geological and metallogenic conditions. Zeng [33] found that the Huangshui River has evodent heavy metal pollution for the contents of $\mathrm{Cd}, \mathrm{Pb}, \mathrm{Hg}$, and $\mathrm{Cr}$ in the muddy sediments, which are all higher than the background values under natural conditions. We infered that Acidiphilium, Acidocella, and Metallibacterium in the upper reaches of the Huangshui River were derived from the sediments along the river, which were affected by strong winds and rainfall. In addition, we identified diverse taxa of potential pathogens, such as Acinetobacter, Pseudomonas, and Aeromonas. The abundance of Acinetobacter was primarily contributed by HS8 and HS4, whereas Pseudomonas and Aeromonas were primarily contributed by HS3 and HS6, respectively. These taxa might result from input of industrial wastewater and household wastewater.

The bacterial community in river water can be affected by many factors including temperature, nutrient concentration, $\mathrm{pH}, \mathrm{DO}, \mathrm{TN}$, and TP [34-36]. In this study, we found that the major driving factors for the bacterial community were $\mathrm{Cr}^{6+}$, altitude and TN. The CCA biplot showed that $\mathrm{Cr}^{6+}$ was significantly amd positively correlated with the dominant genera Acidiphilium and Metallibacterium. Similarly, TN was significantly and positively correlated with Acinetobacter and Bacillus, whereas altitude was negatively correlated with Acidiphilium and Metallibacterium. 
In the current study, the results of the functional profiling using PICRUSt revealed that most of the bacteria were involved in the metabolic pathways, and considerable groups were involved in human diseases and antibiotic resistance. Several studies have reported on environmental bacterial function related to human diseases as reviewed by Sandifer [37]. Antibiotic resistance has been shown to spread throughout the environment through mechanisms such as urban and agricultural runoff, wind, and biological forces such as animals and humans [38]. Given that rivers such as the Huangshui River are the main sources of water for drinking and personal and household hygiene in many developing countries, many people who used these polluted waters without prior treatment might be exposed to negative health effects because of the lack of adequate potable water supplies [39].

\section{Conclusions}

The present study provided a detailed comparison of the bacterioplankton community of the upper reaches of the Huangshui River using high-throughput sequencing for the first time. As a plateau river, the Huangshui River had lower alpha diversity than other plain rivers. Proteobacteria was the dominant phyla, followed by Firmicutes. Given the salt mineral resources widely distributed along the banks of the Huangshui River, Alphaproteobacteria and Gammaproteobacteria were significantly enriched. The predominant bacterial genera were Acidiphilium, Acidocella, Metallibacterium, and Acinetobacter. Diverse taxa of potential pathogens, such as Acinetobacter, Pseudomonas, and Aeromonas were also been identified. The major driving factors for the bacterial community were $\mathrm{Cr} 6+$, altitude and TN. The PICRUSt results revealed that the identified bacteria had diverse functional profiles, but most importantly, a substantial number of these bacteria were involved in human diseases and antibiotic resistance. The study clearly indicated the composition of the plankton bacterial community and its relationship with environmental factors, providing a certain theoretical basis for understanding the microbial ecology and environmental protection in the Huangshui River on the ecotone zone of Qinghai Plateau and Loess Plateau.

\section{Declarations}

\section{Funding}

This work was supported by grants from the National Natural Science Foundation of China (No. 32073023), Qinghai KLPA project (2019/2020), Key Project of Scientific \& Technological Innovation of Hubei Province (2018ABA101), Wuhan Science and Technology Project (2019020701011480) and FEBL project (2016FBZ04).

\section{Conflicts of Interest}

The authors declare no competing interests.

\section{Ethics Approval}


This article does not contain ant studies with human participants or animals performed by any of the authors.

\section{Consent to Participate}

Not applicable.

\section{Consent for Publication}

All list authors haver agreed to be listed and have approved the submitted version of the manuscript.

\section{Code Availability}

Not applicable.

\section{Authors Contributions}

Qianqian Zhang was responsible for the design, data analysis, and writing. Zhenbing Wu performed statistical analyses. Shenglong Jian, Kemao Li, Guojie Wang, and Hongtao Guan conducted sampling and the lab work. Jingwen Hao, Shuyi Wang, and Yaoyao Lin conducted the experimental work. Aihua Li obtained the funding. All authors read, reviewed and edited the manuscript.

\section{References}

1. Fuhrman JA (2009). Microbial community structure and its functional implications. Nat 459(7244), 193-199.

2. Zhou JX, Yang HS, Tang FK, Koide RT, Cui M, Liu YG, et al (2017) Relative roles of competition, environmental selection and spatial processes in structuring soil bacterial communities in the Qinghai-Tibetan Plateau. Appl Soil Ecol 117-118: 223-232.

3. Pernthaler $\mathrm{J}$ (2005) Predation on prokaryotes in the water column and its ecological implications. Nat Rev Microbiol 3(7): 537-546.

4. Yu MD, Liu SJ, Li GW, Zhang H, Xi BD, Tian ZF, et al (2020) Municipal wastewater effluent influences dissolved organic matter quality and microbial community composition in an urbanized stream. Sci Total Environ 705:135952.

5. Simek K, Hornak K, Jezbera J, Nedoma J, Znachor P, Hejzlar J, et al (2008) Spatio-temporal patterns of bacterioplankton production and community composition related to phytoplankton composition and protistan bacterivory in a dam reservoir. Aquat microb ecol 51:249-262.

6. Kirchman DL, Dittel Al, Malmstrom RR, Cottrell MT (2005) Biogeography of major bacterial groups in the Delaware Estuary. Limnol Oceanogr 50(5):1697-1706.

7. Kuang J, Huang L, He Z, Chen L, Hua Z, Jia P, et al (2016) Predicting taxonomic and functional structure of microbial communities in acid mine drainage. ISME J 10(6):1527-1539. 
8. Martins G, Terada A, Ribeiro DC, Corral AM, Brito AG, Smets BF, et al (2011) Structure and activity of lacustrine sediment bacteria involved in nutrient and iron cycles. FEMS Microbiol Ecol 77(3): 666679.

9. Oikonomou A, Filker S, Breiner HW, Stoeck T (2015) Protistan diversity in a permanently stratified meromictic lake (Lake Alatsee, SW Germany). Environ Microbiol 17(6): 2144-2157.

10. Neal C, Robson AJ (2000) A summary of river water quality data collected within the Land-Ocean Interaction Study:core data for eastern UK rivers draining to the North Sea. Sci Total Environ 251252:585-665.

11. Hu ZY, Bao YX, Cheng HY, Zhang L, Ge BM (2009) Research progress on ecology of natural wetland zoobenthos in China. Chin J Ecol 28(5):959-968.

12. Bai XX and Yan CZ (2013) Effects of eco-environment construction projects on soil and water loss in huangshui river basin. Bullet of Soil and Water Conservation 33(3):217-218.

13. Zhao CC, Dong X, Xin WR, Zhang FC, Yang XY (2008) Analysis of Factors of Soil Erosion and Some Ways of Rehabilitation in Huangshui River of Qinghai Province. Res Soil Water Conserv 15(6):200202.

14. Segata N, Izard J, Waldron L, Gevers D, Miropolsky L, Garrett WS (2011) Huttenhower C. Metagenomic biomarker discovery and explanation. Genome Biol 12(6): R60.

15. Langille MGI, Zaneveld J, Caporaso JG, McDonald D, Knights D, Reyes JA, et al (2013) Predictive functional profiling of microbial communities using $16 \mathrm{~S}$ rRNA marker gene sequences. Nat Biotechnol 31: 814-821.

16. Chiu $\mathrm{CH}$ and Chao AN (2016) Estimating and comparing microbial diversity in the presence of sequencing errors. Peer J 4: e1634.

17. Sekiguchi $H$, Watanabe $M$, Nakahara $T, X u B H$, Uchiyama $H(2002)$ Succession of bacterial community structure along the Changjiang River determined by denaturing gradient gel electrophoresis and clone library analysis. Appl Environ Microb P. 5142-5150.

18. Sun YY, Li N, Chen A, Ma GL, Qi ML, Ma Q (2018) Macroinvertebrate community structure and bioassessment of the quality of water in upstream of Huangshui River. J Qinghai Univer 36(4): 65-71.

19. Li N, Yang CJ, Sun YY, Bai LC, Chen A, Ma GL, Ma Q (2017) Community Structure of Macrobenthos and Assessment of Ecosystem Health in Huangshui River, Qinghai Province. Chin Agr Sci Bulletin 33(35): 141-148.

20. Fan LM, Song C, Meng SL, Qiu LP, Zheng Y, Wu W, et al (2016) Spatial distribution of planktonic bacterial and archaeal communities in the upper section of the tidal reach in Yangtze River. Sci Rep 6(1):39147.

21. Hauptmann AL, Markussen TN, Marek S, Olsen NS, Elberling B, Baelum J, et al (2016) Upstream freshwater and terrestrial sources are differentially reflected in the bacterial community structure along a small Arctic River and its estuary. Front Microbiol 7(Pt 1):1474.

22. Yang YZ, Li SG, Gao YC, Chen YY, Zhan AB (2019) Environment-driven geographical distribution of bacterial communities and identification of indicator taxa in Songhua River. Ecol Indic 101:62-70. 
23. Zhang QQ, Jian SL, Li KM, Wu ZB, Guan HT, Hao JW, et al (2020) Community structure of bacterioplankton and its relationship with environmental factors in the upper reaches of the Heihe River in Qinghai Plateau. Environ Microbiol 00(00): 00-00.

24. Liu T, Zhang AN, Wang J, Liu S, Jiang X, Dang CY, et al (2018) Integrated biogeography of planktonic and sedimentary bacterial communities in the Yangtze River. Microbiome 06(01): 16.

25. Newton RJ, Jones SE, Eiler A, Mcmahon KD, Bertilsson S (2011) A guide to the natural history of freshwater lake bacteria. Microbiol Mol Biol Rev 75(1): 14-49.

26. Percent SF, Frischer MR, Vescio PA, Duffy EB, Milano V, Mclellan M, et al (2008) Bacterial community structure of acid-impacted lakes: what controls diversity? Appl Environ Microbiol 74(6):1856-1868.

27. Lin Y, Li D, Zeng S, He M (2016) Changes of microbial composition during wastewater reclamation and distribution systems revealed by high-throughput sequencing analyses. Front Env Sci Eng 10(3): 539-547.

28. Novo A, Andre S, Viana P, Nunes OC, Manaia CM (2013) Antibiotic resistance, antimicrobial residues and bacterial community composition in urban wastewater. Water Res 47(5): 1875-1887.

29. Stevens H, Stubner M, Simon M, Brinkhoff T (2005) Phylogeny of Proteobacteria and Bacteroidetes from oxic habitats of a tidal flat ecosystem. FEMS Microbiol Ecol 54:351-365.

30. Bockelmann U, Manz W, Neu TR and Szewzyk U (2000) Characterization of the microbial community of lotic organic aggregates (river snow) in the Elbe River of Germany by cultivation and molecular methods. FEMS Microbiol Ecol 33, 157-170.

31. Schweitzer B, Huber I, Amann R, Ludwig W, Simon M (2001) Alpha- and beta-Proteobacteria control the consumption and release of amino acids on lake snow aggregates. Appl Environ Microbiol 67, 632-645.

32. Johnson DB, Rolfe S, Hallberg KB, Iversen E (2001) Isolation and phylogenetic characterization of acidophilic microorganisms indigenous to acidic drainage waters at an abandoned Norwegian copper mine. Environ Microbiol 3(10):630-637.

33. Zeng FM (2017) Assessment of Heavy Metal Pollution in Xining Section of the Huangshui River. J Salt Lake Res 25(2): 8-13.

34. Wang P, Chen B, Yuan RQ, Li CQ, Li Y (2016) Characteristics of aquatic bacterial community and the influencing factors in an urban river. Sci Total Environ 569-570: 382-389.

35. Kirchman DL, Dittel A, Findlay SE, Fischer D (2004) Changes in bacterial activity and community structure in response to dissolved organic matter in the Hudson River, New York. Aquat Microb Ecol 35(3):243-257.

36. Li Q, Zhao Y, Zhang X, Wei YQ, Qiu LL, Wei ZM (2015) Spatial heterogeneity in a deep artificial lake plankton community revealed by PCR-DGGE fingerprinting. Chin J Oceanol Limnol 33(3): 624-635.

37. Sandifer PA, Sutton-Grier AE, Ward BP (2015) Exploring connections among nature, biodiversity, ecosystem services, and human health and well-being: opportunities to enhance health and biodiversity conservation. Ecosyst Serv 12:1-15. 
38. Allen HK, Donato J, Wang HH, Cloud-Hansen KA, Davies J and Handelsman J (2010) Call of the wild: antibiotic resistance genes in natural environments. Nat Rev Microbiol 8(4):251-259.

39. Abia ALK, Alisoltani A, Keshri J and Ubomba-Jaswa E (2018) Metagenomic analysis of the bacterial communities and their functional profiles in water and sediments of the Apies River, South Africa, as a function of land use. Sci Total environ 616-617: 326-334.

\section{Tables}

Due to technical limitations, table 1, 2,3 is only available as a download in the Supplemental Files section.

\section{Figures}

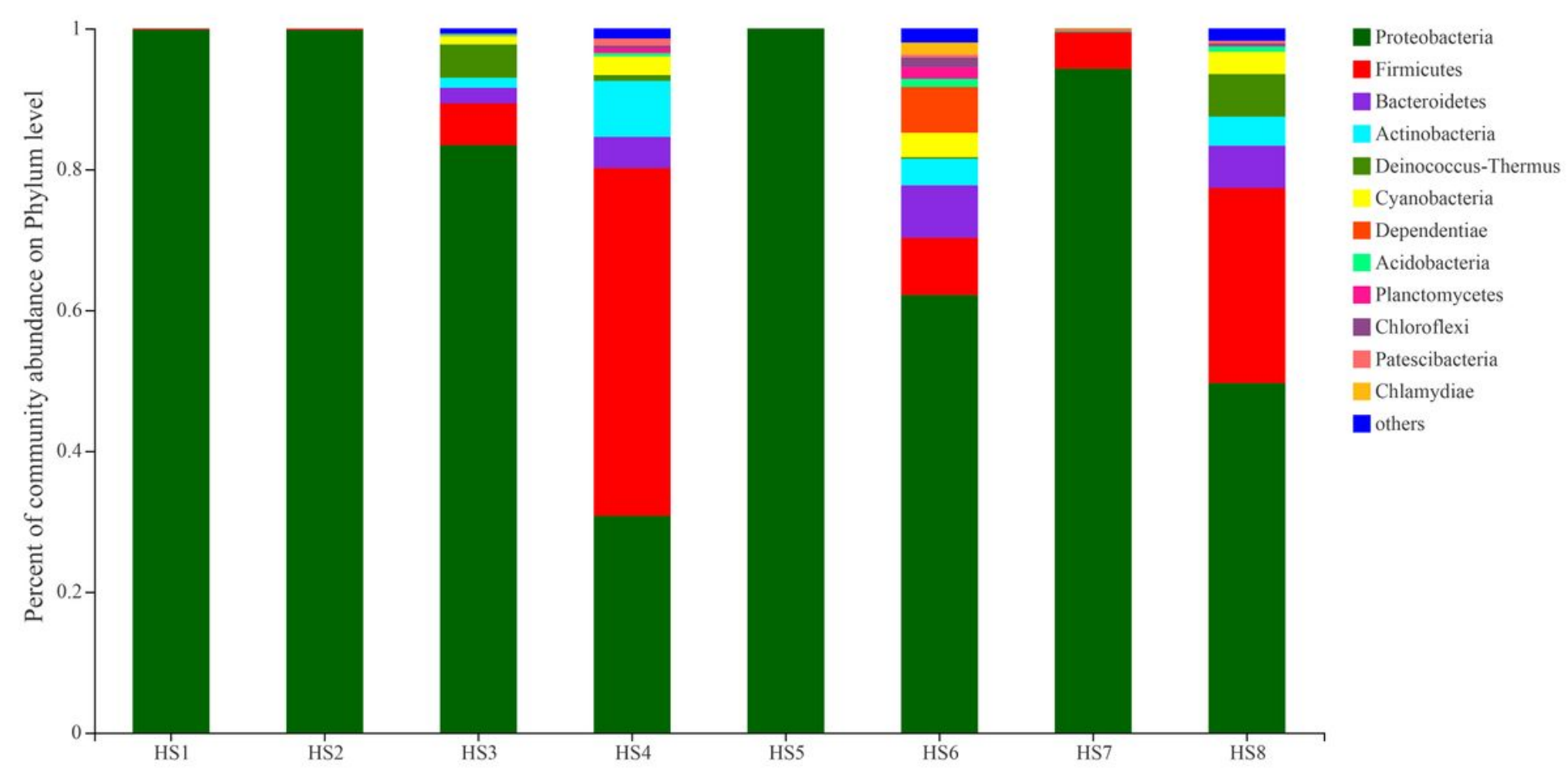

Figure 1

Composition of microorganism groups in each sampling at phylum level 


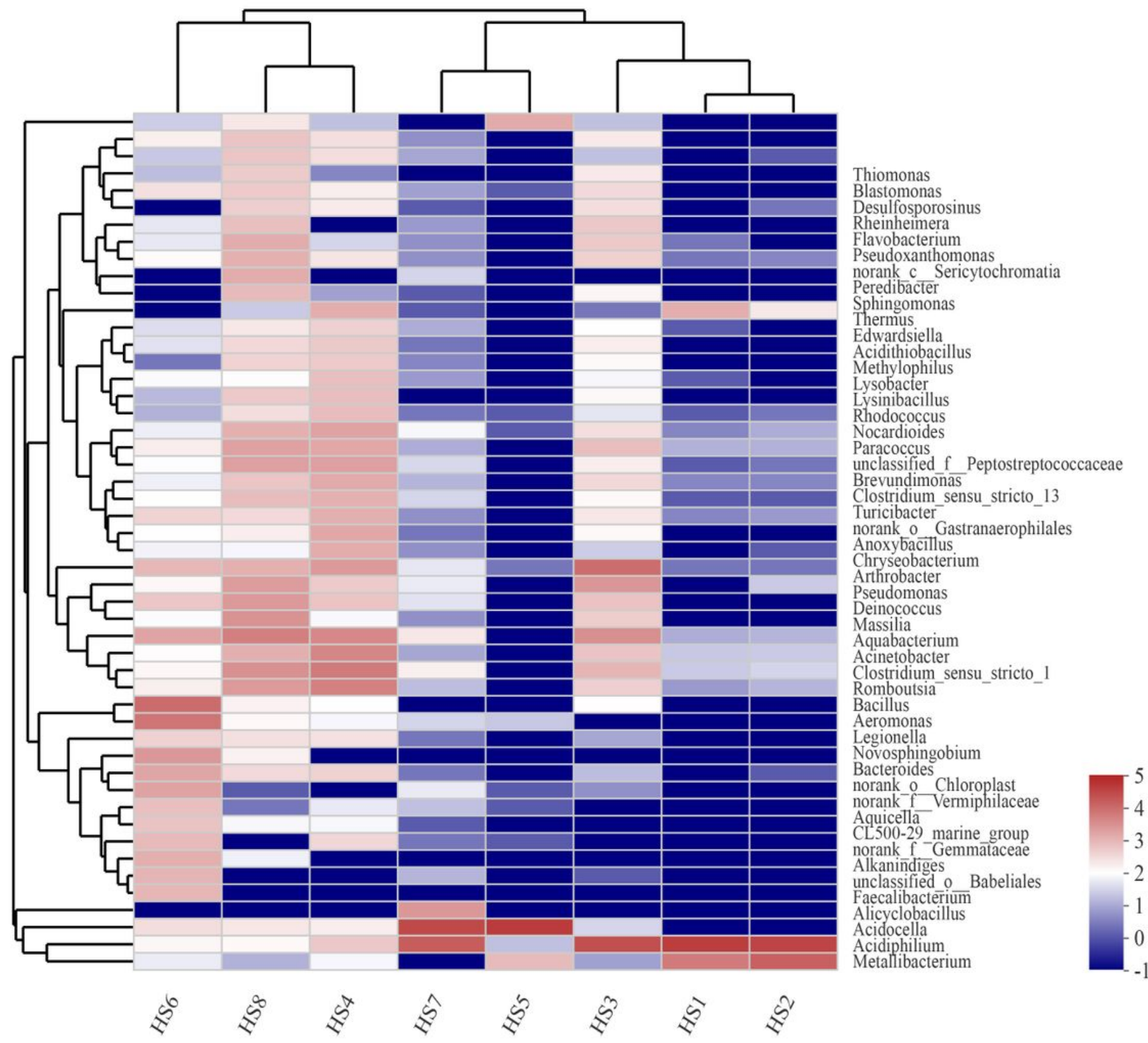

Figure 2

Hierarchical clustering heatmap showing the main bacterial species in different groups at genus level. Each rectangle is colored depending on the log10 value of the taxa percentage as shown in the legend at the left of the plot. The top tree showed the clustering relationship of samples. 


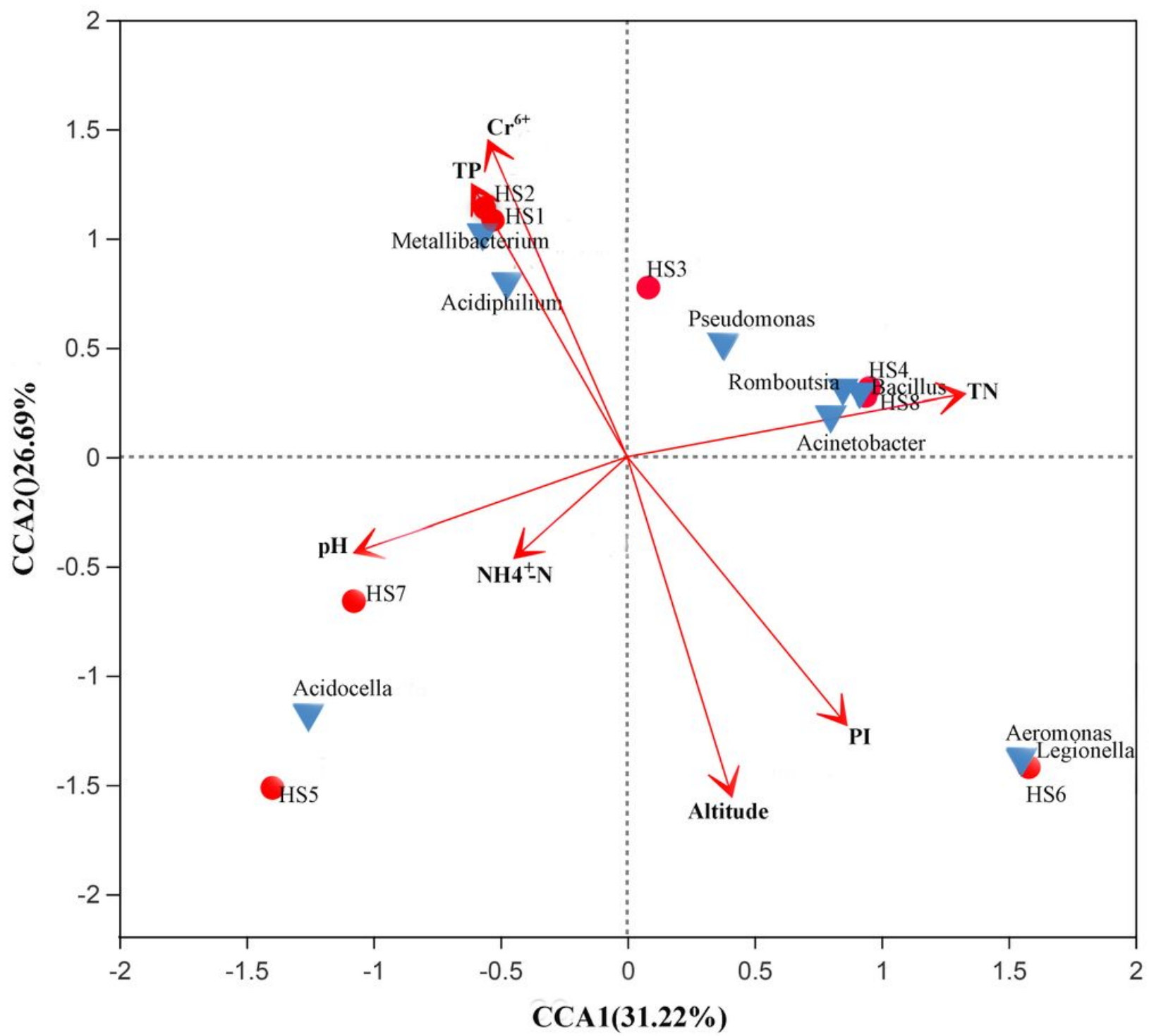

Figure 3

Canonical correspondence analysis (CCA) graph for microorganism community and environmental factors 


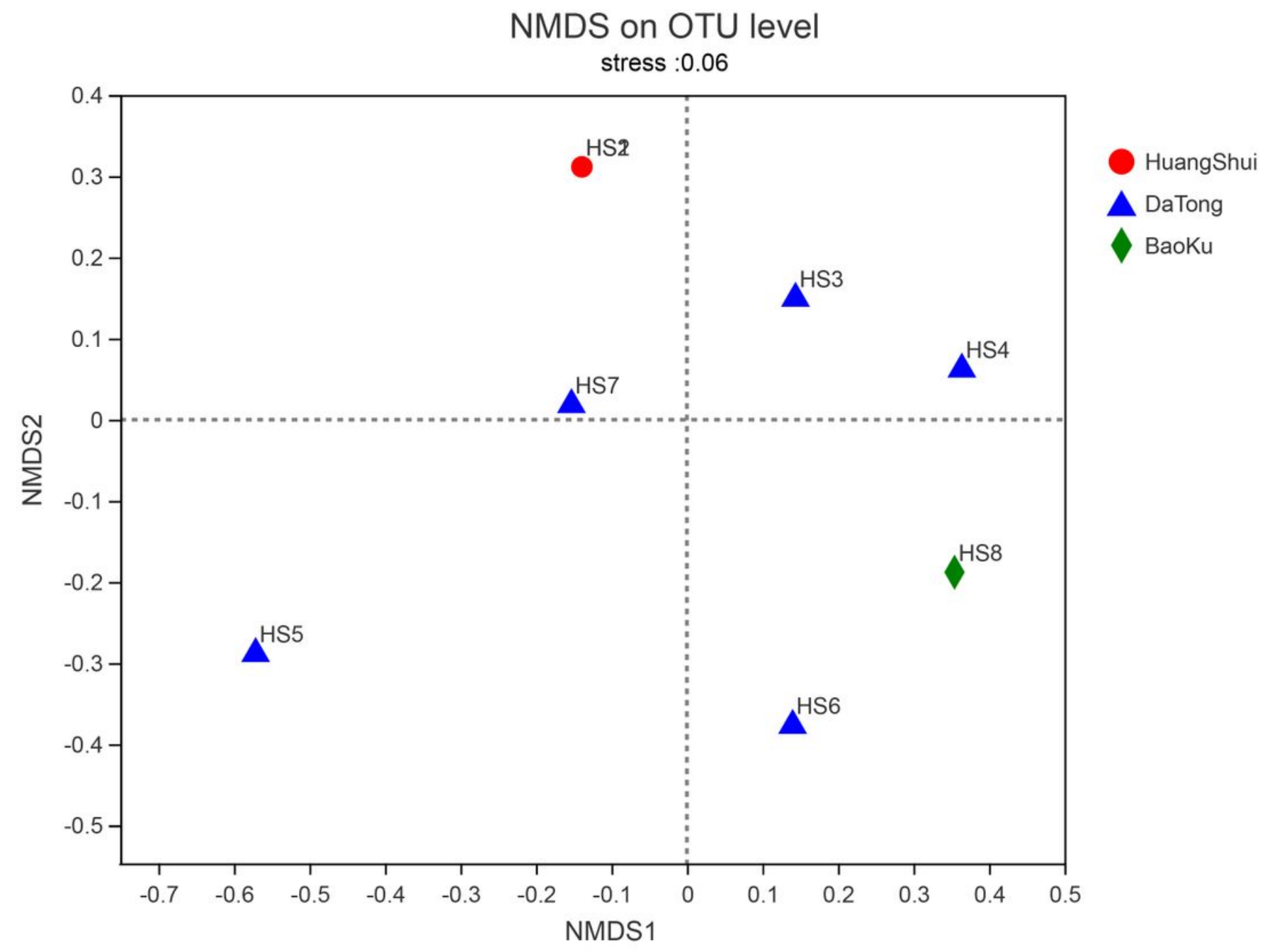

Figure 4

Non-Metrical Dimensional Scale (NMDS) at OUT level based on Bray-Curtis distance matrix 


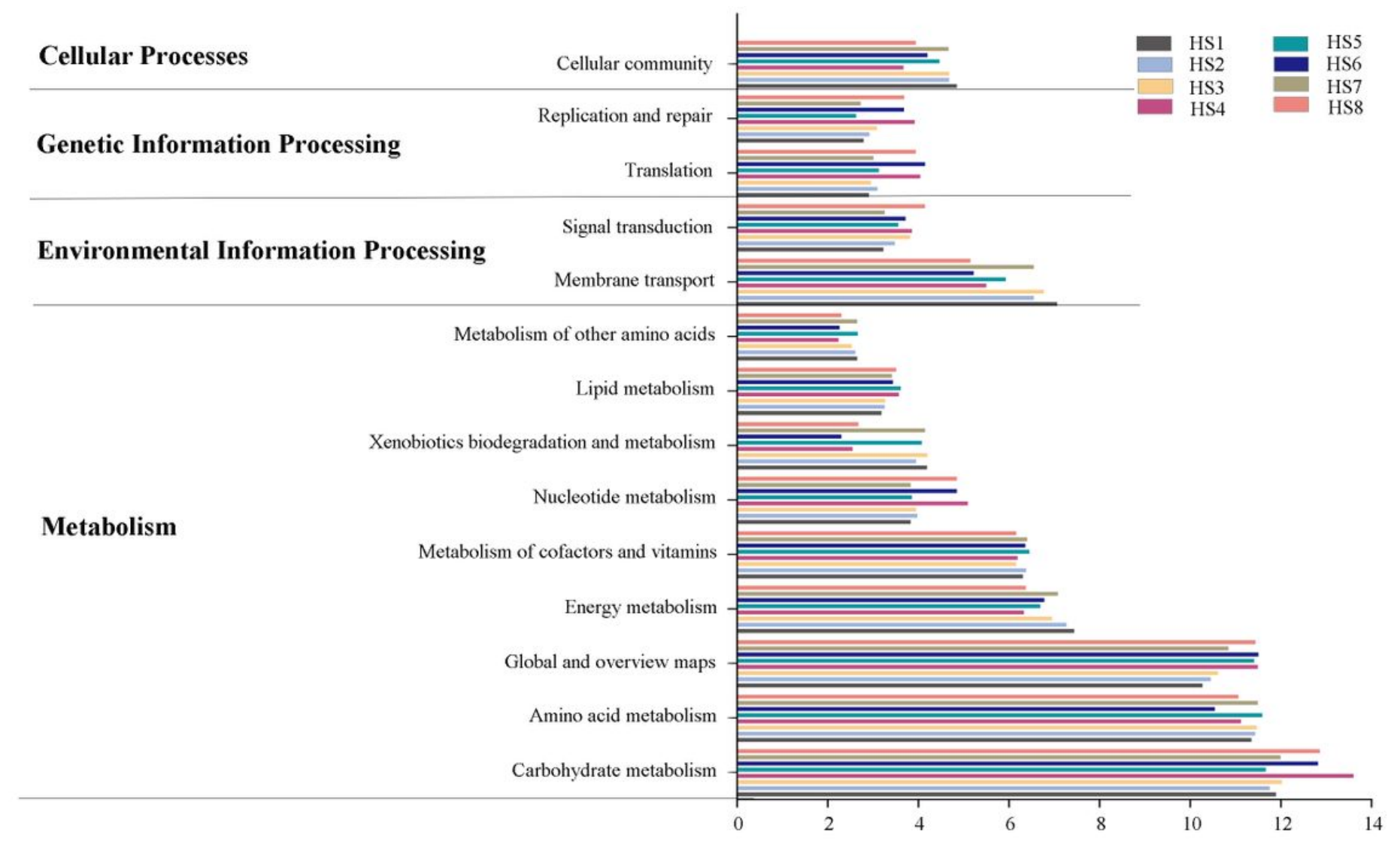

\section{Figure 5}

Predicted functional groups of OTUs in the Huangshui River samples based on KEGG database. Functional groups with less than $1 \%$ relative abundance are not included 

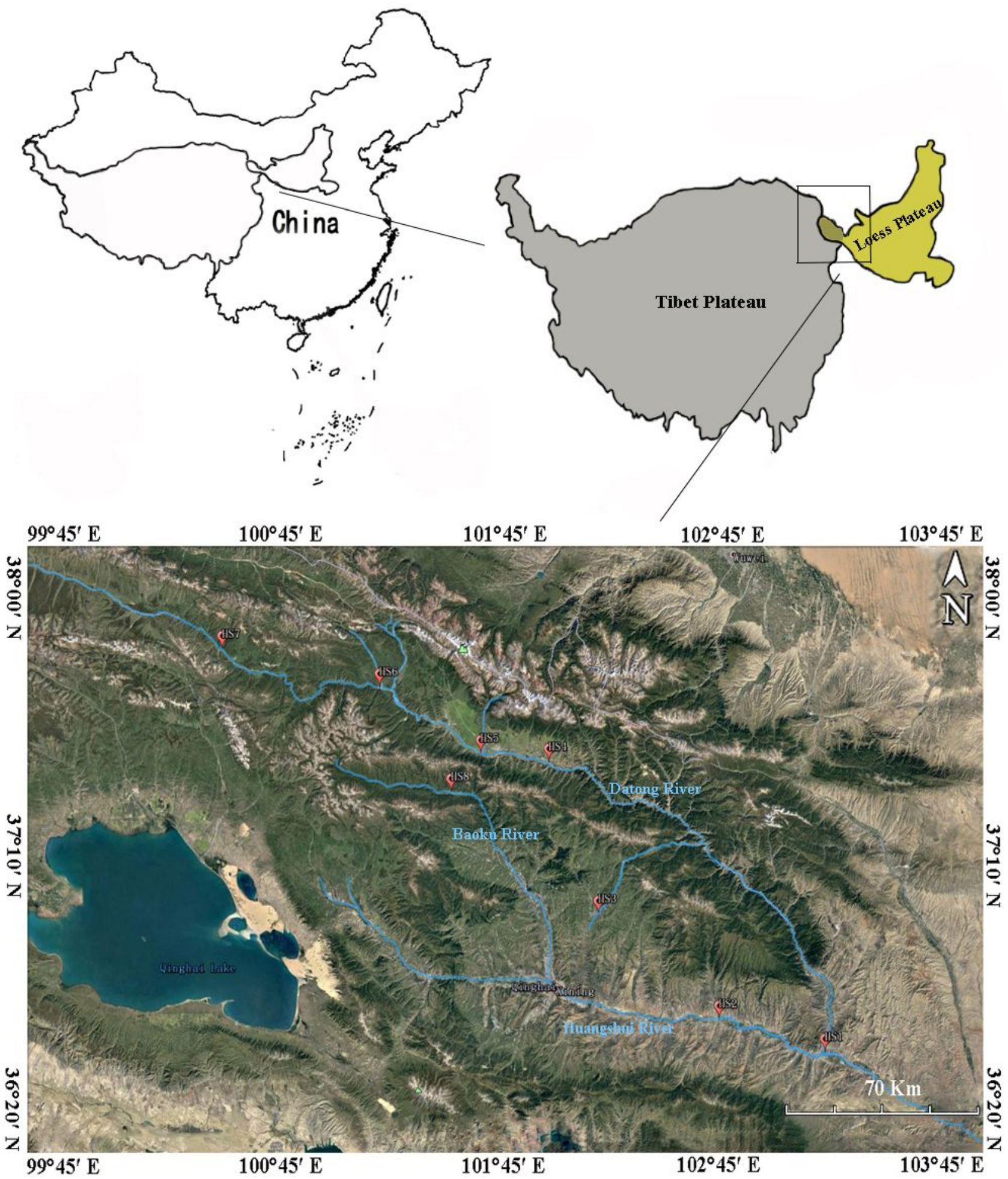

Figure 6

Distribution of sampling sites in the Huangshui River. Map image and geographic information were cited from Google Earth Pro (version 7.1.8.3036). Specific latitude and longitude information about each sampling site are shown as follows: HS1 $\left(36^{\circ} 20^{\prime} 28.9^{\prime \prime} \mathrm{N}, 102^{\circ} 50^{\prime} 07.4^{\prime \prime} \mathrm{E}\right), \mathrm{HS} 2\left(36^{\circ} 28^{\prime} 39.2^{\prime \prime} \mathrm{N}\right.$, $\left.102^{\circ} 25^{\prime} 10.8^{\prime \prime} \mathrm{E}\right), \mathrm{HS} 3\left(36^{\circ} 50^{\prime} 07.0^{\prime \prime} \mathrm{N}, 101^{\circ} 58^{\prime} 00.5^{\prime \prime} \mathrm{E}\right), \mathrm{HS} 4\left(36^{\circ} 19^{\prime} 20.4^{\prime \prime} \mathrm{N}, 101^{\circ} 48^{\prime} 57.8^{\prime \prime} \mathrm{E}\right)$, HS5

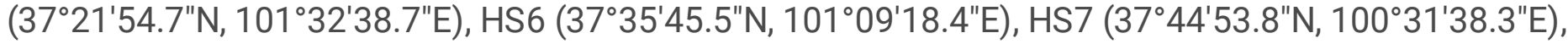


HS8 $\left(37^{\circ} 15^{\prime} 09.3^{\prime \prime} \mathrm{N}, 101^{\circ} 24^{\prime} 51.8^{\prime \prime} \mathrm{E}\right)$. Note: The designations employed and the presentation of the material on this map do not imply the expression of any opinion whatsoever on the part of Research Square concerning the legal status of any country, territory, city or area or of its authorities, or concerning the delimitation of its frontiers or boundaries. This map has been provided by the authors.

\section{Supplementary Files}

This is a list of supplementary files associated with this preprint. Click to download.

- Table1.pdf

- Table2.pdf

- Table3.pdf

- FigureS1.jpg 